\title{
Obesity and Reproduction
}

\author{
Joao Batista A Oliveira ${ }^{1,2}$ \\ ${ }^{1}$ Center for Human Reproduction Prof. Franco Junior, Ribeirão Preto/SP - Brazil \\ ${ }^{2}$ Paulista Center for Diagnosis Research and Training, Ribeirao Preto/SP - Brazil
}

Obesity is associated with multiple interrelated disorders such as insulin resistance/diabetes, hypertension, dyslipidemia, sleep apnea - all contributing collectively to the diagnosis of a metabolic syndrome, that reduces life expectancy (Flegal et al., 2013). Metabolic changes in obesity may also affect reproduction.

In women, obesity is associated with a higher incidence of ovulatory disorders and idiopathic infertility (ASRM, 2015). On the other hand, obese women under treatment for infertility may face additional problems, such as the need for higher doses of drugs to induce/stimulate ovulation, oocyte morphological changes, reduction in fertilization and implantation rates, and embryo quality (ASRM, 2015; Provost et al., 2016). Compared to women of normal body weight, obese women submitted to IVF may present reduced rates of clinical pregnancy and live births, with an increased rate of abortion (Provost et al., 2016). In addition, obese pregnant women have a higher incidence of maternal and fetal complications, such as gestational diabetes, hypertensive disorders of pregnancy and increased perinatal morbidity/mortality (Aune et al., 2014).

With respect to men, male obesity has been linked to reduced rates of pregnancy and live births (Campbell et al., 2015). However, studies on specific relationships between semen parameters and obesity have been contradictory. Although different studies have shown correlations between increased obesity and changes in sperm parameters, although selectively (MacDonald et al., 2010, Sermondade et al., 2013, Campbell et al., 2015), others did not report adverse effects (Bandel et al., 2015). On the other hand, recent studies point to a negative association between body weight and the very integrity of sperm DNA (Fariello et al., 2012; Taha et al., 2016); however, these results are not unanimous (Bandel et al., 2015; Campbell et al., 2015). Spermatogenesis requires a controlled testicular environment and intact endocrine signaling through the hypothalamic-pituitary-testicle axis; and the impact of obesity on fertility can be attributed mainly to the endocrine mechanisms that alter this relationship (MacDonald et al., 2010; Fariello et al. 2012; ASRM, 2015). Moreover, the preferential buildup of toxic substances and fat-soluble endocrine disruptors in adipose tissue, and hyperthermia resulting from the buildup of adipose tissue around the scrotum cause oxidative stress to the testes, thus broadening these alterations (Fariello et al., 2012; Sermondade et al., 2013, Taha et al., 2016).

In conclusion, even considering the controversies, weighty reduction and lifestyle interventions should be included in the recommendations to obese infertile couples.

Keywords: Obesity, reproduction, infertility, body weight.

\section{REFERENCES}

ASRM. Practice Committee of the American Society for Reproductive Medicine, 2015. Obesity and reproduction: a committee opinion. Fertil Steril., 2015,104:1116-26.

Aune D, Saugstad OD, Henriksen T, Tonstad S. Maternal body mass index and the risk of fetal death, stillbirth, and infant death: a systematic review and meta-analysis. JAMA 2014; 311:1536-46.

Bandel I, Bungum M, Richtoff J, Malm J, Axelsson J, Pedersen HS, Ludwicki JK, Czaja K, Hernik A, Toft G, Bonde JP, Spanò M, Malm G, Haugen TB, Giwercman A. No association between body mass index and sperm DNA integrity. Hum. Reprod. 2015; 30:1704-1713.

Campbell JM, Lane M, Owens JA, Bakos HW. Paternal obesity negatively affects male fertility and assisted reproduction outcomes: a systematic review and meta-analysis. Reprod Biomed. Online. 2015; 31:593-604.

Fariello RM, Pariz JR, Spaine DM, Cedenho AP, Bertolla RP, Fraietta R. Association between obesity and alteration of sperm DNA integrity and mitochondrial activity. BJU Int. 2012; 110:863-7.

MacDonald AA, Herbison GP, Showell M, Farquhar CM. The impact of body mass index on semen parameters and reproductive hormones in human males: a systematic review with meta-analysis. Hum Reprod Update. 2010: 16:293-311.

Provost MP, Acharya KS, Acharya CR, Yeh JS, Steward RG, Eaton JL, Goldfarb JM, Muasher SJ. Pregnancy outcomes decline with increasing body mass index: analysis of 239,127 fresh autologous in vitro fertilization cycles from the 2008-2010 Society for Assisted Reproductive Technology registry. Fertil Steril. 2016; 105:663-9.

Sermondade N, Faure C, Fezeu L, Shayeb AG, Bonde JP, Jensen TK, Van Wely M, Cao J, Martini AC, Eskandar M, Chavarro JE, Koloszar S, Twigt JM, Ramlau-Hansen CH, Borges E Jr, Lotti F, Steegers-Theunissen RP, Zorn B, Polotsky AJ, La Vignera S, Eskenazi B, Tremellen K, Magnusdottir EV, Fejes I, Hercberg S, Lévy R, Czernichow S. BMI in relation to sperm count: an updated systematic review and collaborative meta-analysis. Hum Reprod Update. 2013; 19; 221-31.

Taha EA, Sayed SK, Gaber HD, Abdel Hafez HK, Ghandour N, Zahran A, Mostafa T. Does being overweight affect seminal variables in fertile men? Reprod Biomed Online. 2016 in press 